\title{
Optimalisasi Kepuasan Kerja Guru
}

\author{
Hardianto \\ Universitas Pasir Pengaraian \\ hardiantocally@gmail.com
}

\begin{abstract}
ACDP (Analytical and Capacity Development Partnership) data suggests that $10 \%$ of teachers did not attend school and 14\% of those attending did not attend the class. This number indicates the teacher is not satisfied with their work. Teacher job satisfaction needs to be improved so that education can run better. Teachers who are satisfied at work will feel happy with their work, happy with the work environment and so on. Unsatisfied teachers can cause low performance and even increase the desire to move or stop working. Therefore, efforts need to be made to optimize teacher work satisfaction. Two ways that can be done to improve teacher job satisfaction are by giving appropriate rewards and increasing motivation.
\end{abstract}

Keywords: Job Satisfaction, Optimization, Teacher Performance

\section{Article Info}

Received date: 19 Mei $2018 \quad$ Revised date: 20 Agustus 2018 Accepted date: 8 Desember 2018

\section{PENDAHULUAN}

Upaya peningkatan kualitas pendidikan harus dilakukan secara terus menerus.Saat ini peringkat pendidikan Indonesia masih kalah dibandingkan negara-negara lain. Untuk tingkat ASEAN, pendidikan Indonesia hanya berada pada peringkat lima di bawah Singapura, Brunei Darussalam, Malaysia dan Thailand. Sementara di dunia, Indonesia berada pada peringkat 108 dengan skor 0,603. Hanya sebanyak $44 \%$ penduduk menuntaskan pendidikan menengah. Sementara $11 \%$ murid gagal menuntaskan pendidikan alias keluar dari sekolah (http//siedoo.com).

Banyak faktor yang menyebabkan rendahnya peringkat pendidikan Indonesia. Salah satu faktornya adalah guru atau tenaga pendidik. Guru memiliki peran yang cukup besar dalam menentukan keberhasilan pendidikan. Seseorang yang menjadi guru hendaknya memiliki empat kompetensi, yaitu kompetensi pedagogik, kompetensi kepribadian, kompetensi sosial dan kompetensi profesional. Menurut Bujang Rahman saat ini baru $51 \%$ guru yang telah memenuhi persyaratan minimal. Dari 3 juta guru di Indonesia, hanya 51 persen yang sudah mengantongi lisensi Strata Satu (www.unila.ac.id).

Dalam Undang-Undang No 14 Tahun 2005 tentang Guru dan Dosen dinyatakan bahwa tugas guru adalah mendidik, mengajar, membimbing, mengarahkan, melatih, menilai dan mengevaluasi peserta didik pada pendidikan anak usia dini jalur pendidikan formal, pendidikan dasar dan pendidikan menengah. Untuk memenuhi tugas guru tersebut, mereka dituntut memiliki kepuasan kerja yang tinggi. Guru yang tidak memiliki kepuasan kerja tentu saja tidak akan mampu melaksanakan tujuh tugas guru itu secara maksimal. 
Job satisfaction is a positive feeling about one's work and work setting (Schemerhorn Hunt, Osborn dan Bein, 2010: 14). Perasaan positif tentang kerja dan pekerjaan akan menyebabkan rasa senang dalam diri seseorang dan akan meningkatkan kinerja mereka. Guru yang memiliki kepuasan kerja akan senang dengan pekerjaan dan lingkungan kerja mereka. Perasaan senang ini dapat dilihat dari kesenangan guru untuk berada di sekolah atau mengajar di kelas.

Tahun 2016 menurut David Harding dari ACDP mengemukakan bahwa ada $10 \%$ guru yang tidak hadir di sekolah (http://jabarprov.go.id). Selanjutnya ada $14 \%$ guru yang hadir di sekolah tetapi tidak hadir di kelas. Angka ini jelas menunjukkan bahwa kepuasan kerja guru belum tercapai. Tidak tercapainya kepuasan kerja guru ini tentu saja mengakibatkan tujuan pendidikan juga tidak akan tercapai.

Dalam melaksanakan pembelajaran guru tentunya membutuhkan sarana dan prasarana yang memadai. Kelengkapan sarana prasarana di sekolah dapat menyebabkan guru memiliki kepuasan dalam melaksanakan pekerjaan. Saat ini banyak sekolah yang belum memenuhi standar. Dirjen Pendidikan Dasar dan Menengah Hamid Muhammad menyatakan bahwa dari banyaknya sekolah di 500 kabupaten/kota yang ada hanya 70 persen yang memenuhi standar (http//nasional.tempo.com). Permasalahan utama untuk pemenuhan standar itu adalah persoalan sarana prasarana dan kompetensi guru.

Berkenaan dengan kompetensi guru diketahui pada tahun 2016 dilaksanakan Pengembangan Keprofesian Berkelanjutan (PKB) yang menyasar sekitar 460.000 guru. Saat dites akhir, dari target renstra 6,5, hasilnya rata-rata nilai tes itu 6,49 . (http://kabar24.bisnis.com). Belum tercapainya target mengindikasikan kepuasan kerja guru juga masih rendah.
Berdasarkan temuan-temuan di atas, penulis tertarik membuat tulisan ilmiah tentang Optimalisasi Kepuasan Kerja Guru. Tulisan ini diharapkan dapat memberikan gambaran bagaimana agar kepuasan kerja guru bisa tercapai. Guru yang memiliki kepuasan kerja diyakini akan lebih mampu mewujudkan tujuan pendidikan nasional.

Guru merupakan faktor penting dalam keberhasilan pendidikan. Dalam UndangUndang No. 14 Tahun 2005 yang dimaksud dengan guru adalah pendidik profesional dengan tugas utama mendidik, mengajar, membimbing, mengarahkan, melatih, menilai, dan mengevaluasi peserta didik pada pendidikan anak usia dini jalur pendidikan formal, pendidikan dasar, dan pendidikan menengah. Melihat tugas guru tersebut, maka guru dituntut memiliki kompetensi tertentu.

Terdapat empat kompetensi yang harus dimiliki seorang guru. Kompetensi itu adalah kompetensi pedagogik, kompetensi profesional, kompetensi sosial dan kompetensi kepribadian. Kompetensi pedagogik berkaitan dengan penguasaan keterampilan mengajar, kompetensi profesional berkaitan dengan penguasaan materi ajar. Kompetensi sosial berkaitan dengan kemampuan membina hubungan sosial dan kompetensi kepribadian berkaitan dengan diri pribadi seorang guru.

Dalam Undang-Undang No 14 Tahun 2005 juga dinyatakan bahwa sebagai agen pembelajaran guru berfungsi untuk meningkatkan mutu pendidikan nasional. Guru yang mampu melaksanakan fungsi tersebut tentulah guru yang memiliki kepuasan kerja. Kepuasan kerja akan mendatangkan rasa senang terhadap profesi yang digeluti.

Beberapa pengertian kepuasan kerja dikemukakan para ahli. Gibson, Ivancevic, Donnelly dan Konopaske (2012:102) mengemukakan Job satisfaction is an attitude that individuals have about their jobs. It results from their perceptions of their jobs, based on factors of the work environment, such as the 
supervisor's style, policies, and procedures, work group affiliation, working conditions, and fringe benefits. Wagner dan Hollenbeck (2010:106) menyatakan bahwa Job satisfaction is "a pleasurable feeling that results from the perception that one's job fulfills or allows for the fulfillment of one's important job values. Dua pengertian di atas menekankan bahwa kepuasan kerja merupakan perasaan dalam diri seseorang yang merasa senang dengan pekerjaannya.Perasaan senang itu timbul setelah berhasil memenuhi nilai pekerjaannya yang berdasarkan lingkungan kerja.

Lebih lanjut Luthans (2011:141) mengemukakan Job satisfaction is a result of employees' perception of how well their job provides those things that are viewed as important. Pendapat senada juga dikemukakan Locke (2009:146) yang menyebutkan Satisfaction is the form in which one experiences having gained or possessed a value. Apabila dikaitkan dengan guru, maka kepuasan kerja guru merupakan rasa senang dalam diri seorang guru terhadap pekerjaan yang telah mereka lakukan.

\section{PEMBAHASAN}

Kepuasan kerja guru sangat penting untuk mewujudkan tujuan pendidikan yang optimal. Guru yang merasa puas dalam bekerja akan semakin bersemangat dalam bekerja. Hal ini tentu saja akan dapat meningkatkan kinerja mereka. Agar kepuasan kerja guru semakin meningkat perlu diperhatikan hal-hal berikut ini:

\section{Penghargaan dapat meningkatkan kepuasan kerja guru}

Pemberian penghargaan yang sesuai dengan harapan guru akan dapat meningkatkan kepuasan kerja mereka. Kepuasan kerja dan kinerja pada dasarnya saling berkaitan dan dipengaruhi oleh penghargaan. Hal ini sesuai dengan pendapat Schemerhorn, Hunt, Osborn dan Bein (2010:76) yang menyebutkan "job satisfaction and performance are intertwined, influencing one another, and mutually affected 192 by other factors such as the availability of rewards". Penekanan terhadap penghargaan yang mempengaruhi kepuasan kerja disampaikan oleh Gibson, Ivancevic, Donnelly dan Konopaske (2012:175) "Satisfaction is influenced by how satisfied employees are with both intrinsic and extrinsic rewards".

Adanya pengaruh pemberian penghargaan terhadap kepuasan kerja sesuai dengan hasil penelitian Aktar S, Uddin dan Sachu (2013:1-8) yang menyebutkan "The result from this study examined and determined the relationship between rewards and employees' performance and job satisfaction. Based on a result from paired sample t-test, Pearson correlation analysis, and regression analysis it showed that there is a strong positive linear relationship between rewards and employees' performance and job satisfaction of the pharmaceutical industry in Bangladesh". Penelitian ini menyimpulkan bahwa untuk meningkatkan kepuasan kerja perlu ditingkatkan penghargaan. Lumban Gaol dan Siburian (2018:71) mengemukakan bahwa salah satu cara yang dapat dilakukan kepala sekolah dalam meningkatkan kinerja guru adalah dengan memberikan penghargaan bagi guru yang berhasil atau berkinerja dengan baik.

Penelitian Sarwar dan James Abugre (2013-22-32) juga menunjukkan bahwa terdapat hubungan yang positif dan signifikan antara reward dan job satisfaction.: "There is a significant relationship between higher rewards and higher job satisfaction of employees. We use Chi-Square (x2) as test statistics at significance level of .05\% (i.e. $\alpha=$ $.05)$, and the degree of freedom $(d f=3)$, Computed Chi-square (X2) $=3.204$ and ChiSquare $(X 2)$ critical $=7.815$."

Penghargaan yang diberikan kepada guru agar mereka memperoleh kepuasan dalam bekerja adalah penghargaan yang sesuai dengan harapan. Guru yang melakukan tindakan atau beban kerja yang sama harus memperoleh penghargaan yang sama. Perbedaan dalam 
pemberian penghargaan akan menyebabkan kecemburuan bagi guru. Schemerhorn, Hunt, Osborn dan Bein (2010:77) mengemukakan "It suggests that the right rewards allocated in the right ways will positively influence both performance and satisfaction, which also influence one another".

Penghargaan (finansial maupun non finansial atau intrinsik ataupun ekstrinsik) yang diberikan kepada guru akan dapat mempengaruhi kepuasan kerja mereka. Penelitian Zaraket dan Saber (2017: 369-378) menyebutkan terdapat hubungan yang signifikan penghargaan finansial terhadap kepuasan kerja karyawan. "A regression analysis was used to examine the impact of financial reward on job satisfaction and employee performance. The result indicates there is significant relation of the financial reward on job satisfaction for the Blue Collar employees $(R 2=0.253, p<0.05)$ ". Sementara penelitian Muhammad dan Faiza Maqbool (2015:65-74) menerangkan "Descriptive analysis shows that the mean values of independent variable extrinsic reward are 3.2571 and mean value of dependent variable job satisfaction is 3.8381 which mean respondents agree that extrinsic reward increase their job satisfaction level".

Di Indonesia terdapat setidaknya tiga status guru, yaitu guru PNS, guru tetap yayasan dan guru honorer. Penghargaan untuk guru PNS terutama penghargaan finansial diyakini sudah mencukupi, terlebih bagi guru yang sudah bersertifikasi.Sedangkan bagi guru honorer penghargaan finansial umumnya dirasakan masih sangat kurang. Sangat banyak guru yang menerima gaji jauh dibawah Upah Minimum Regional (UMR) daerah. Sedangkan guru tetap yayasan juga sangat tergantung kepada sehat tidaknya ekonomi yayasan. Guru tetap yayasan yang sudah besar dan sehat penghargaan finansial bisa lebih baik dari guru PNS. Sementara guru tetap yayasan yang kurang sehat dari sisi ekonomi juga tidak jauh lebih baik dari guru honorer.

Selain penghargaan finansial, penghargaan non finansial juga mesti diperhatikan. Guru akan tetap merasakan kepuasan kerja apabila profesinya sebagai guru diakui dan dihargai. Kepala sekolah bisa memberikan pujian atas prestasi atau kinerja guru.Selain pujian, pemberian sertifikat, suasana kerja yang nyaman juga merupakan bentuk penghargaan non finansial.

Berdasarkan pembahasan di atas diketahui bahwa optimalisasi kepuasan kerja guru dapat dilakukan dengan memberikan penghargaan yang sesuai dengan harapan mereka. Dengan adanya kepuasan kerja guru akan mampu menampilkan perilaku kewargaan organisasi (memberikan kemampuan lebih dari tugas utama) bagi sekolah. Hal ini sesuai dengan pendapat Gibson, Ivancevic, Donnelly dan Konopaske (2012:106) yaitu "although job satisfaction doesn't influence quantity and quality of performance, it does influence citizenship behaviors, turnover, absenteeism, and preferences and opinions about unions".

\section{Motivasi dapat meningkatkan kepuasan kerja guru}

Motivasi yang meningkat diyakini akan mampu meningkatkan kepuasan kerja guru. Griffin dan Moorhead (2014:97) menyatakan "motivation factors affect one dimension, ranging from satisfaction to no satisfaction". Semakin tinggi motivasi guru maka akan semakin tinggu pula kepuasan kerja mereka. Kepala sekolah dapat meningkatkan motivasi guru dengan meningkatkan kualitas hubungan diantara mereka. Hal ini sesuai dengan pendapat Armstrong (2007:44) yang mengemukakan "the quality of the relationship between manager and employee is the biggest motivational factor at work, and has more influence on job satisfaction than anything else".

Pendapat selanjutnya yang menyatakan bahwa motivasi merupakan faktor yang 
Kelola: Jurnal Manajemen Pendidikan, Vol. 5, No. 2, Juli-Desember 2018

mempengaruhi kepuasan kerja adalah dari Gibson, Ivancevic, Donelly dan Konopaske (2012:172) yaitu "the social and motivational factors increased performance quantity, learning the task, goal acceptance, group commitment, and satisfaction". Hasil penelitian Khan, Rizwan, Arshad, Fahad (2013:226-243) menyebutkan bahwa motivasi seseorang berbanding lurus secara positf dengan kepuasan kerja. Semakin meningkat motivasinya, maka semakin puas akan pekerjaannya dalam organisasi. Hasil penelitiannya juga menyebutkan bahwa penghargaan intrinsik memberikan pengaruh positif terhadap motivasi karyawan. Griffin dan Moorhead (2014:98) selanjutnya menyatakan bahwa "motivation factors such as achievement and recognition were often cited by people as primary causes of satisfaction and motivation."

Berdasarkan pendapat-pendapat di atas diketahui bahwa untuk meningkatkan kepuasan kerja guru dapat dilakukan dengan meningkatkan motivasi mereka. Kepala sekolah atau pengawas bisa menjadi faktor motivator ekstrinsik bagi guru. Selain itu guru juga diharapkan mampu meningkatkan motivasi mereka dalam melaksanakan pekerjaan.

Motivasi bersumber dari dalam dan luar diri. Kepala sekolah sebagai motivator eksternal pada dasarnya juga akan meningkatkan motivasi guru. Penerapan gaya kepemimpinan yang melayani (servant leadership) dapat memicu motivasi kerja guru yang pada akhirnya meningkatkan kepuasan kerja mereka. Sari dan Supramono (2016:274) mengemukakan bahwa dua karakteristik servant leadership yang menonjol di SMA S Kota Salatiga, yaitu develop people dan provide leadership. Selanjutnya Lumban Gaol (2017:217) mengemukakan bahwa kepemimpinan kepala sekolah sangat menentukan peningkatan dan pengembangan sekolah. Tanpa adanya kemampuan yang memadai dalam mengimplementasikan gaya kepemimpinan, kepala sekolah akan menemukan berbagai kesulitan dalam mewujudkan sekolah yang efektif

Motivasi akan dapat meningkatkan kepuasan kerja. Sementara kepuasan kerja yang tinggi akan dapat mengurangi keinginan pindah atau berhenti guru. Schemerhorn, Hunt, Osborn dan Bein (2010:143) mengemukakan "Job satisfaction can also effect turnover, or decisions by people to terminate their employment, simply put, dissatisfied workers are more likely than satisfied workers to quit their jobs". Apabila guru banyak yang pindah tentu saja sekolah akan mengalami kesulitan mewujudkan tujuannya.

\section{SIMPULAN}

Berdasarkan pembahasan di atas diketahui bahwa optimalisasi kepuasan kerja guru dapat dilakukan dengan dua cara: 1) kepuasan kerja guru dapat ditingkatkan dengan memberikan penghargaan yang sesuai harapan guru, dan 2) kepuasan kerja guru dapat ditingkatkan dengan meningkatkan motivasi guru. Kepala sekolah diharapkan mampu sebagai motivator ekstrinsik bagi guru.

\section{DAFTAR PUSTAKA}

Aktar, Serena, Md. Zia Uddin, M. Kamaruzzaman Sachu.2013. The Impact of Rewards on Job Satisfaction and Employees Performance in Bangladesh: A Comparative Analysis Between Pharmaceutical and Insurance Industries. International Journal of Business and Management Invention.. Vol 2. Issue 8. Agustus. hal: 1-8

Armstrong, Michael. 2007. A Handbook of Employee Reward Management in Practice. 2nd Edition. KoganPage London Philadelphia.

Gibson,James L., John M. Ivancevich, James H. Donnelly Jr, Robert Konopaske. 2012. Organizations, Structure, Processes. 
14th Edition. McGraw-Hill Irwin. New York.

Griffin, Ricky W. dan Gregory Moorhead. 2014.Organizational

Behavior.

Managing, People and

Organization.South-Western Cengage

Learning. USA.

Khan, Muhammad Yousuf, Muhammad Rizwan, Muhammad Ibrahim Arshad, Muhammad Fahad Anwar. 2013. Impact of Employee Motivation on Job Satisfaction With Respect to Corporate Social Responsibility and Rewards. Journal of Public Administration and Governance. Vol 3. No 3. hal: 226-243

Locke, Edwin A..2009. Handbook of Principles of Organizational Behavior. Indispensable Knowledge for EvidenceBased Management. 2nd Edition. Edited by John A. Locke. Wiley and Sons.

Lumban Gaol, Nasib Tua. 2017. Teori dan Implementasi Gaya Kepemimpinan Kepala Sekolah. Jurnal Kelola. Vol. 4. No. 2. hal: 213-219

Lumban Gaol, Nasib Tua dan Siburian, Paningkat. 2018. Peran Kepala Sekolah Dalam Meningkatkan Kinerja Guru. Jurnal Kelola. Vol. 5. No. 1. hal: 66-73

Luthans, Fred. 2011. Organizational Behavior An Evidence-Based Approach. 12th Edition. McGraw-Hill Irwin. New York.

Muhammad, Noreen, Faiza maqbool. 2015. Impact of Extrinsik Rewards on JobSatisfaction of Banking Sector Employees of Karachi. Pakistan. IOSR Journal Of Business nad Management. Vol 17. Issue 1. hal: 65-74

Sari, Handita dan Spramono. 2016. Kepemimpinan yang Melayani di Sekolah Menengah Tingkat Atas
Swasta Kota Salatiga. Jurnal Kelola. Vol. 3 No. 2.hal: 265-276

Sarwar, Shagufta, James Abugre. 2013. The Influence of Rewards and Job Satisfaction on Employees in The service Industry. The Business \& Management Revew.Vol 3 No. 2.hal: 22-32

Schermerhorn Jr, John R., James G. Hunt, Richard N. Osborn, Mary Uhl Bien. 2010. Organizational Behavior. 11th Edition. John Wiley \& Son Inc. USA.

Undang-Undang Republik Indonesia No 14 Tahun 2005 Tentang Guru dan Dosen.

Wagner,John A dan John R. Hollenbeck. 2010. Organizational Behavior. Securing Competitive Advantege. Routledge. New York and London.

Zaraket,Wael S. dan Farouk Saber.2017. The Impact of Financial Reward on Job Satisfaction and Perfotmance: Implication for Blue Collar Employees. China-USA Business Review.Vol.16. No 8.hal: 369-378

https://siedoo.com/berita-4965-peringkatpendidikan-indonesia-dan-budayaburuknya/ Diakses 8 Mei 2018

https://www.unila.ac.id/baru-51-persen-gurupenuhi-kualifikasi-pendidikan/ Diakses 7 Mei 2018

http://jabarprov.go.id/index.php/news/16352/2 016/03/07/Tiga-Masalah-Guru-diIndonesia Diakses 7 Mei 2018

https://nasional.tempo.co/read/840126/kement erian-pendidikan-hanya-70-persensekolah-penuhi-standar Diakses 8 Mei 2018

http://kabar24.bisnis.com/read/20171123/255/ 712068/ini-3-masalah-utama-gurutenaga-pengajar Diakses 8 Mei 2018 